\title{
Pteknokultura
}

\#Avizanda Pérez, M. (2015). Salsa Roja: Podemos como programa revelación de la temporada televisiva. Revista Teknokultura, Vol. 12(1), 147-152.

Recibido: 20-03-2015

Aceptado: 07-04-2015
Link Open peer review:

http://revistas.ucm.es/index.php/TEKN/pages/view/opr-274

\section{Salsa Roja: \\ Podemos como programa revelación de la temporada televisiva}

\author{
Red spice: \\ Podemos as the season's television revelation
}

\author{
María Avizanda Pérez \\ Grupo de Investigación Cibersomosaguas \\ maria.avizanda@gmail.com
}

\section{Resumen}

"Salsa Roja: Podemos como programa revelación de la temporada televisiva" es una reflexión sobre Podemos, las televisiones y la relación simbiótica que se ha generado entre ambos, desde la popularización de Pablo Iglesias, hasta la actual percepción de lo que el partido considera una campaña mediática de descrédito ante su auge. El efecto Podemos ha modificado las parrillas televisivas, en una suerte de reality político que dispara los audímetros, pero de consecuencias imprevisibles para el proyecto. 


\section{Palabras Clave}

Podemos, televisión, periodismo, audiencias.

\section{Abstract}

"Red spice: Podemos as the season's television revelation" is a reflection on Podemos, television channels and the symbiotic relationship they have built up between them. From the popularization of Pablo Iglesias up to what today the party considers a media campaign of discredit. The Podemos effect has transformed television "roastings" into a sort of political reality show that boosts audience figures, but has unpredictable consequences for the project.

\section{KeYWORDS}

Podemos, television, journalism, audiences figures. 
Era el chico que hablaba para que le entendiera mi madre. Ese fue el nacimiento mediático de Pablo Iglesias. Fue esa cara con marco de tele incorporado la que reconocieron las mayorías en las papeletas del $25 \mathrm{M}$ y los cinco escaños. El líder del movimiento que ha dado un giro a la manera de ser y hacer política de muchos españoles se coló por la grieta de las teles. Son gente lista, atenta, preparada. Porque hay que ser todo eso para saber colarse sin pagar en los espacios del infotainment televisivo. Hay un mantra que se repite en las redacciones: "Cuéntalo para que lo entienda mi madre". Eso lo han sabido entender en Podemos. Hay que contarlo fácil. Y, por supuesto, emocionar. Pero sobre todo hay que saber convencer para vencer después. Han rentabilizado su cuota de pantalla al máximo. Mientras los programas monetizan el hallazgo, Podemos hace caja social y pedagogía política para mayorías televisivas.

A nadie se le escapa que la televisión se rige por simplistas y caprichosos mecanismos. Los que llevaron a entender ante todo a Pablo Iglesias como animal mediático, más allá de su papel como elemento disruptivo en política. Los de la tele, tan abducidos en sus incesantes búsquedas de nuevos activos y personajes en pro de los beneficios del chiringuito, integraron al elemento exótico con discurso incorporado en los debates. La Salsa Roja que es Podemos como ingrediente esencial del nuevo filón mediático. Hace unos años, arrasaba en el primetime de los sábados una telebasura del corazón llamada Salsa Rosa. Porque en la tele da un poco lo mismo el color, rosa o rojo, televisión que vende al fin y al cabo, así son las lógicas del medio. Y así mutan quienes la hacen. Un ejemplo es que Salsa Rosa fue dirigido por Sandra Fernández, primero directora del debate político de sábado festivo que es La Sexta Noche, y que después saltó sin despeinarse a intentar replicar el éxito en Telecinco, con Un Tiempo Nuevo. Hasta el nombre del programa da idea del alcance del efecto Podemos; inaugura nuevos tiempos y nuevas parrillas. Diría que Podemos supone el estreno de un género televisivo. El reality político. La vida en directo. Con sus roles, sus personajes y los guiones, con acotaciones que van más allá de lo político, con los enfrentamientos personales aderezando las intervenciones en los debates.

Pero la calurosa bienvenida inicial ha dado un giro inevitable en la trama, los perfiles mediáticos de sus dirigentes han ido mutando en virtud de sus males revelados. Errejón y sus problemas con la justicia por el contrato con la Universidad de Málaga, Monedero y Hacienda, Bescansa y su desliz confiando a un periodista sus planes de prohibir la actividad de los bancos 
fraudulentos, Monedero —-siempre Monedero, el provocador que más y mejor alimenta a los medios - y su llamada a la redacción de la Cadena SER tratando de parar la difusión de la noticia. Hasta Pablo Iglesias ha perdido su antes inagotable paciencia ante los micrófonos.

Podemos lo interpreta como una campaña, política y periodística, orquestada contra ellos ante su ascenso en las encuestas. ¿Acaso esperaban que no fuera así, creían que el reality político no iba a necesitar alimentarse de nuevas tramas fraudulento-conspiratorias, directamente proporcionales a su ascenso en las encuestas? Más madera. Más leña al share, que es de goma. Así que la simbiosis televisión-Podemos se ha sostenido incorporando nuevos rostros al plantel de contertulios habituales de las cadenas. Podemos aprende rápido, pero sobre la marcha, a manejar los códigos de los grandes medios porque sabe que este camino es el que lleva a las mayorías que habitan los mundos analógicos. Pero esa capacidad mutante y devastadora de la televisión, aún están empezando a calibrarla. La última: Ramón Espinar, candidato del partido a la Comunidad de Madrid, se ha visto sorprendido en medio de una pista de circo en prime-time festivo, con razones pero sin tablas mediáticas, defendiendo su versión de lo que pasa en Venezuela. Pero sucede que a Telecinco le interesa Venezuela básicamente como trending topic con gresca incorporada. Cuidado con meterte en las pistas de algunos circos, porque puedes acabar convertido en payaso. Pedro Sánchez, secretario general del PSOE, no tuvo su mejor idea con su criticada intervención por teléfono en el buque insignia de la telebasura actual, Sálvame, para reconquistar el voto perdido de su presentador, Jorge Javier Vázquez. Después lo empeoró describiendo el programa como "referente social". "Tenemos que comunicarnos con diferentes formatos y en diferentes programas", añadió después en El programa de Ana Rosa. En la tele, como en la política, los formatos se copian.

Más pruebas del efecto Podemos. Del amor-odio en la relación con los medios. El último hito que fue noticia: la entrevista de Pedro Piqueras a Pablo Iglesias en el plató de informativos Telecinco, la tele del Gran Hermano y Belén Esteban, fue vista por 4.269.000 espectadores y anotó un $22,2 \%$ de cuota de pantalla. ${ }^{1}$ Es la entrevista a un político más vista desde 2004. La de entonces fue a José María Aznar en su primera entrevista concedida tras el 11-M y la derrota electoral del 14-M. Paradojas de la historia política, Pablo Iglesias no estuvo en ese plató pero sí que intervino en cierto modo en el guión: en enero de este año ha revelado que fue en la Facultad de Ciencias Políticas y Sociología de la Complutense donde se gestó el famoso SMS que convocó a la concentración ante la sede del PP en la jornada de

\footnotetext{
${ }^{1}<$ https://twitter.com/mediasetcom/status/570161546661388288>
} 
reflexión, que fue la previa a la histórica derrota de la derecha de Aznar. La revelación la ha hecho además en su propio programa de televisión, Otra vuelta de Tuerka, en ese rol un tanto sui generis y cuestionable de político-entrevistador, en un intercambio de papeles que también convirtió en entrevistado -y confesor- al entrevistador más carismático de este país, Iñaki Gabilondo. Quién se lo iba a decir, que sentaría a Gabilondo a su mesa, cuando partieron de su medio independiente, La Tuerka. Allí comenzó a gestarse su narrativa mediática de hoy, aprovechando el ensayo para adaptar sus formas y discursos a los medios convencionales, cada vez más debilitados y faltos de ideas, cada vez menos capaces de emocionar a los espectadores, igual que los partidos políticos de siempre a los votantes. Podemos ha cambiado la manera de entender la política y la participación ciudadana, pero también ha cuestionado la manera de hacer periodismo, aunque sean los periodistas quienes -es su trabajo- les cuestionen a ellos. Pero les necesitan. Se necesitan mutuamente.

La brecha digital es el reto, y la del género, y la de las exclusiones en general, y todas ellas aún pasan por esa transversalidad que comparte todo efecto viral: ganar también la partida en televisión y en los medios generalistas, porque esas son otras audiencias de mentalidades analógicas, aun mediatizadas por el discurso unidireccional de los medios de comunicación convencionales. Mientras la tele sigue anclada en el medio sin enterarse de lo novedoso del mensaje, Podemos revisita la democracia 3.0 en las redes sociales. El uso político de las redes inaugurado por Podemos en España ha capacitado al ciudadano para entenderse como un medio en sí mismo, para entender las lógicas de una comunicación que las nuevas generaciones ya no entienden como telespectadores, sino también como hacedores de política, gestores del conocimiento y de la información.

La red ha sacado a los periodistas de las centralitas que eran las redacciones de los medios, hemos perdido el monopolio de la información. Porque ahora las redes la propagan más rápido y la decisión de qué es noticia, la agenda mediática la deciden cada vez más la red y el activismo informativo. Se acabó el sentido de la propiedad, la información ya no es patrimonio de los periodistas. Desde la humildad de entenderla como un bien colectivo puede que renazca el nuevo periodista, libre ya del peso y el privilegio de su firma. La gestión de la información en horizontal, siguiendo la lógica de los nuevos medios y las redes sociales.

El periodismo maltrecho de hoy se mueve más que nunca en los márgenes de los beneficios netos y la información en bruto, abrumados por la el ritmo descontrolado de las redes y la crisis. El periodismo digital está por inventarse. Ha trasladado el viejo periodismo en papel a internet, no ha crecido con las lógicas digitales. ¿Lo han entendido ya los medios digitales? ¿Pueden definir su identidad y eficacia como tales? Se enfrentan al reto de construir 
su propia identidad, de superar las formas del papel impreso. O nos damos prisa en construir nuestro rol como modestos artesanos digitales de nuestro oficio y recuperamos la credibilidad perdida, o hasta los servidores y compiladores de noticias nos adelantarán por la derecha. O por la izquierda, dará lo mismo en una prensa donde la ideología fue absorbida por la economía.

Lloran los grandes medios por el poder perdido. El cuarto poder lamenta que se cuestione su poderío, que el ciudadano ya no le lea, ni le compre, ni le escuche. Mientras se lamenta el sector de la pérdida de 10 mil puestos de trabajo en España en los últimos seis años años y los 70 medios desaparecidos, se frota las manos la banca, que no necesita ni siquiera sentarse en un consejo de administración del grupo PRISA para editar sus diarios. ¿Para qué, cuando Botín es el dueño de su deuda? Antes la excusa para la deslealtad a la verdad eran los anunciantes; ahora los trabajadores de las grandes corporaciones mediáticas sufren en silencio las consecuencias de la financiarización de los medios.

Celebremos la democratización que han traído las redes sociales, y el auge de los medios independientes. La emancipación del ciudadano de su mal entendido ser ciudadano solo de reclamar en ventanilla, que dice Iñigo Errejón. Quizá deberíamos celebrar por higiene ética y profesional, el principio del fin del pesebrismo mediático que traen consigo.

Leo que el Sindicato de Obreros del Campo, de esa fuerza muy viva que es Cañamero, se acerca a Podemos en el sur. Ellos mantienen viva la utopía de que la tierra es para quien la trabaja. Los periodistas estamos lejos de entender que la televisión es de quienes la ven, y no de quienes la hacemos. Sobre todo la pública, TVE, a la que todo este viraje político le ha pillado mirando hacia la derecha, hacia el lado de la tele-irrealidad. Debería ser uno de los retos de Podemos si al final resulta que Puede: no sucumbir ante posibles amistades generadas por la sintonía con algunas televisiones privadas e invertir el esfuerzo en devolver la dignidad de lo público a TVE. Porque están los datos del CIS, y luego están los datos del share televisivo. Están los programas políticos, y están los de la tele. Los primeros no se los lee casi nadie, los segundos, los vemos casi todos. Y merecen recuperar algún día la calidad perdida en la lucha por la audiencia y los intereses partidistas. 